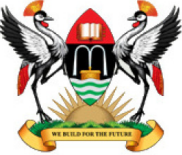

East African School of

Higher Education Studies \& Development
Makerere Journal of Higher Education

ISSN: $1816-6822 ; 4(2)(2013) 235-245$

DOI: http://dx.doi.org/10.4314/majohe.v4i2.8

(C) The Author(s) 2013

Reprints \& permission: EASHESD

http://ajol.info/majohe

\title{
Reflections on the Indigenous Knowledge embedded in University Language Teacher Education Curriculum
}

\author{
Mathias Bwanika Mulumba ${ }^{1, *}$, Anthony Mugagga Muwagga ${ }^{1}$ \\ ${ }^{1}$ College of Education and External Studies, Makerere University [*Corresponding author: \\ mbwanika@educ.mak.ac.ug]
}

\begin{abstract}
The paper examines the current university language Teacher Education Curriculum and the African indigenous knowledge embedded therein. The paper draws its discussion and reflections from findings got from a study carried out in Makerere University School of Education language education students and lecturers. The study purposively studied students of English and Luganda language education. The study was guided by three study objectives namely; examining the nature of indigenous knowledge found in the language teacher curriculum assessing the knowledge, skills and values embedded in the language teacher curriculum plus the teacher trainees' awareness of indigenous knowledge in the study materials. The findings reveal that the current language teacher curriculum mortifies indigenous knowledge, values and skills because it is built on foreign pedagogical paradigms. The study concluded that both the language teacher trainers and trainees have little knowledge about indigenous knowledge. It is also concluded that indigenous knowledge is not taken as an essential component in the training of both English and Luganda teachers. The contribution of indigenous knowledge to the knowledge, skills and attitudes of trainees is negligible and most often not within examinable topic. The absence of a formidable anchor in terms of indigenous knowledge, where knowledge, skills and attitudes set off and sprout, has crippled the originality and creativity of both English and Luganda teacher trainees.
\end{abstract}

Keywords: Teacher education; Language education, Indigenous knowledge

\section{$1 \quad$ Introduction}

Critiques of contemporary language teacher education argue that the under pining philosophy behind teacher language curriculum is euro-centred and thus creates teachers who are divorced from their indigenous languages and the implied values and beliefs. The most salient attack to language teacher 
curriculum is based on the ground that: in Sub Saharan Africa (SSA) there seem to be a well calculated and intentional move by the missionaries, colonial and African post colonial governments to annihilate indigenous knowledge systems through the introduction of foreign languages as both the official means of communication and instruction. In all of Sub Saharan Africa the introduction of formal education meant the profaning of indigenous languages and replacing them with those of the colonial masters for example in East Africa English was introduced and became the pivot for social status. Ssekamwa (1997) reveals that the issue of language was seen as a very crucial point by the missionaries many of whom believed that if African leant the European languages then they would by implication also get civilized since they would follow that which they had learnt from the different literature books studied. While Akankwasa (1997), notes that formal education was not meant to facilitate the survival of indigenous cultures but a tool to annihilate them since many missionaries and other colonial masters believed that African indigenous knowledge systems were diabolic and mastery of foreign or western languages became a symbol of being schooled and civilized. As a result indigenous languages were in most cases relegated to peripheral and non official occasions such as family talks and private discussions. It may not be wrong to deduce from the above arguments that the teaching of indigenous languages in tertiary institutions of learning is also modelled on western pedagogy and philosophy which are necessarily not meant to edify their knowledge base.

\subsection{Inception of Missionary Education and Language Teacher Education Curriculum}

Different authors on Missionary activity in Africa such as Kagoda, (2002, Ssekamwa 1997, Ibingira, 1973, reveal that missionaries played a salient role in introducing formal education in Sub Saharan Africa. Their main focus seemed to have been evangelization but in the process their pedagogy ended up alienating the individual from their traditional patterns of behaviour, and in the process profaned the indigenous languages and at times promoted a culture of flunkeyism which culminated in producing schooled but not educated people (Kwitonda, 1995, Akankwasa 1997 ). Ssekamwa (1997) further reveals that over $60 \%$ of Africans cannot read and write well in their first language. This revelation was also alluded to by the NAPE report 2010/12, which further reveals that formal education undermined indigenous knowledge systems and idealized European languages as evidence of being civilized (Ngũgĩ wa Thiong'o in his book "The River Between, Chinua Achebe in his books Things fall Apart and No longer at Ease ) 
In most of Sub Saharan Africa (SSA) the first and most used literacy books are those written by the first Christian missionaries for example in Uganda the first written books in all Ugandan languages were written either by the Missionaries from the Church Missionary society, The Mill Hill Fathers, White Fathers or the Comboni missionaries ( Kampala Arch diocesan archives 1879 -2012) The missionaries wrote simple indigenous language dictionaries, simple language teaching and study guides, begun translating the Bible and other liturgy books which became the pivot for literacy in the whole of Uganda.

The missionaries in order to facilitate literacy translated Latin, English or French books and in the process super imposed the cultures found in these translations on the African with dire consequences such creating an African in colour but ridden with western metaphysical and axiological orientations which were a result of the knowledge gotten form the literacy sources based on non African ideas. These in the long run have had both positive and negative implications for the knowledge, beliefs and values cherished and transmitted in private and public arenas.

On the other hand all the English study books at all levels of education in SSA Uganda in particular save the few African writer series, were drawn from either Judeo-Christian tradition, Anglo-American writer series in both grammar, poetry, novels, plays and pedagogy. These were meant to create intellectuals with Euro-American mind and thought. This might be the very reason why critiques of missionary and euro-centred education in Africa complained of. These critiques are evident in Walter Rodney's book "How Europe underdeveloped Africa", Paulo Freire's "Pedagogy of the Oppressed" and Franz Fanon's "wretched of the Earth"

Contrary to the indigenous African tradition, intra-ethnic and inter-ethnic communication and transfer of information and knowledge was predominantly mediated by indigenous languages (The Nordic African Institute, 2011). Language as a medium of communication and instruction in schools and institutions if spiced with indigenous beliefs and values would be very instrumental in perpetuating and enriching indigenous knowledge. Lamentation is high that language teacher curriculum in Uganda seems to be deficient of indigenous knowledge. The language teacher curriculum in the country emphasises linguistic description, and pedagogy (Mulumba, 2011); which are modelled on the English language education curriculum. The curricula of the widely taught local and regional languages such as Luganda and Kiswahili respectively were designed basing on the English language curriculum. The language teacher curricula therefore seem to be alien to teacher trainees' value and knowledge background and do not appear to empower them with skills, creativity and originality which are supposed to be the basic strands for their environment, values and beliefs. 


\subsection{Philosophical Orientation to Indigenous Knowledge and Education}

This study and discussion is underpinned by the Afro centric view about knowledge and education which presupposes that reality is embedded not only that which is perceivable but also that which is unperceivable. To the African that which he/she cannot communicate through verbal or non verbal means is not reality. Dei, (1994: 3), notes that Afro centricity is concerned with 'an investigation and understanding of phenomena from a perspective grounded in African-centred values and epistemology. In order to validate and critique African experiences in an educational and scholarly manner, this implies that language becomes a pivot for not only transmitting knowledge but a base for both axiological and metaphysical edification.

On the other hand in line with (Wittgenstein Ludwig, 1889-1951) discussions on language, in Africa, language should have pictured or mirrored the African's reality but a profaned language naturally will profane the reality. Africans talk about what they see, have been told or think about. To the African language is not only a communication tool but a ground for their existence. This is well elaborated in Mbiti (1980) arguments on being. That is "I am because I am able to communicate with and to others." To the African language and communication is the pivot for sustainable leaving and development. Indigenous knowledge systems are a more dynamic conception of culture and as the ultimate foundation upon which decision making takes place (Warren, Slikkerveer \& Brokensha, 1995). Language is not only a means of communication but an arena in which counsel and reverence to the metaphysical realities are made more explicit (Obeng 1991). Therefore African philosophy of education and indigenous knowledge, values and beliefs are intertwined. According to Ociti (1990) it is very hard to talk about African indigenous education without talking about the African philosophy of education which is the study of beliefs, values and knowledge particular to Africa.

\section{$2 \quad$ Methodology}

This paper provides a critique of the nature of indigenous knowledge skills and values embedded in the language teacher curriculum. The study used Luganda and English language as case studies. The study used mainly ethnographic modes of inquiry. The paper draws and discusses findings drawn from a purposively selected sample of 600 Luganda and English language Bachelor of Arts with Education students of Makerere University and ten language University lecturers. Makerere University was chosen because it houses over $60 \%$ of the Luganda and English undergraduate students in Uganda, Luganda was chosen because it is the most prominent and oldest indigenous language 
taught in not only Makerere University but in Uganda at large (Ssekamwa 1997, Mulumba, 2011) while English was selected for study because it is the official language both for instruction and communication in Uganda. The study sample included students drawn from academic years 2005 to 2010 of the College of Education and External Studies (CEES), School of Education (SOE) Makerere University. The students were sampled to include year 1, 2 and 3 language trainee teachers. The detail is presented in Table 1.

Table 1: Sample

\begin{tabular}{ll}
\hline Academic year & Sampled students \\
\hline $2005 / 2006$ & 183 \\
$2006 / 2007$ & 221 \\
$2007 / 2008$ & 141 \\
$2008 / 2009$ & 94 \\
$2009 / 2010$ & 107 \\
Total number of Sampled students & 746 \\
\hline
\end{tabular}

Data in Table 1 reveals that the total number of students involved in the study was 746 and it also reveals that there is a gradual decline in the number of students offering language education in Makerere University.

\section{$3 \quad$ Findings and Discussion}

The study findings are presented under titles which correspond to the titles derived from the study objectives namely:

- examining the nature of indigenous knowledge found in the language teacher curriculum;

- assessing the knowledge, skills and values embedded in the language teacher curriculum plus ;

- Student teacher trainees' awareness of indigenous knowledge in the study materials.

\subsection{Nature of indigenous knowledge in language education Curriculum}

Findings in this section were drawn from both documentary analysis and interview responses from both the students and lecturers. The documentary sources included poetry, novels and grammar books used in actual pedagogy. The literary analysis revealed that the language education curriculum has a few strands of indigenous knowledge which are basically manifested in instructional materials such as textbooks. The most salient of these are the African writer series for example those written by Chinua Achebe in his master 
piece Things Fall Apart or translated in Luganda "Eby'edda Bisasika" Edward Kawere's ( 1958) book in Luganda titled: Zinunula Omunaku, which gives an elaborate treatise of the Ganda culture in pre-colonial Buganda context. However $78 \%$ of the students revealed that they mainly depend and read EuroAmerican books and materials because they are cheaper and available. They also noted that most Luganda books are hard to read. This showed that students seem not to know classic Luganda. Classic Luganda meant Luganda which is spiced with idioms; proverbs and wise sayings not used in common pedestrian speech. One student said:

"It is easier to access a European book than most African written books. African books are not only scarce but they are also expensive "(One student complaining about African writer series books)

While another said:

"Reading a Luganda novel is like reading Latin and yet I am a Muganda. Our parents and the education system has crippled us since many of us cannot read our own language well" (Statement made by a third year Luganda language Education student)

On the other hand findings from the documentary review of the education language curriculum revealed that the most cited indigenous knowledge strands were in the areas of learning systems such as methods of imparting knowledge; human health especially on traditional medicine; and agricultural practices particularly on planting, harvest and storage activities. The findings reveal that there is a marked difference between the amount of indigenous knowledge in the English teacher curriculum and the Luganda teacher curriculum for teacher trainees at Makerere University. Textbooks and other instructional materials written or co-authored by African writers had more traits of indigenous knowledge than those written by their counterparts from the west. The Luganda teacher curriculum had some courses that had items embedded in indigenous knowledge. Both the students and lecturers revealed that Luganda language education would have had a lot of indigenous knowledge but the pedagogy used leans more on the euro-American paradigm thus this constrains and westernizes indigenous knowledge got therein. To this one student said:

"On a number of occasions our teachers teach us Luganda culture but cite English examples to me this kills the essence of Kiganda culture meant to be transmitted in the study." (One of the Language education students in a study group discussion).

The above findings imply that the teaching of language education constrains indigenous knowledge stances. 


\subsection{Indigenous knowledge, skills, values and embedded in the language teaching-learning process}

The study also sought to establish if language students understood indigenous knowledge gotten from the teaching and learning process. One of the participants commented:

I can't tell you exactly how indigenous knowledge is integrated in the teaching process. But, one thing for sure is that we [teacher trainers and trainees] discuss these issues [indigenous knowledge], though such knowledge is not properly demarcated in the courses we teach.

Failure for the language teacher curriculum to put emphasis on indigenous knowledge explains why teacher trainers do not give prominence to this kind of knowledge during the teaching-learning process. In all the interviews that were held, trainees reiterated the fact that indigenous knowledge is neither taught nor discussed during the lecture time. It was only one trainee in one of the focus group discussions who observed:

Sometimes, our lecturers talk about indigenous knowledge especially when they are explaining certain features in language. For instance some examples to explain certain concepts in language are bent towards indigenous knowledge.

The study also revealed that some language student teachers queried the relevancy of indigenous knowledge to language teachers observed:

But, actually do we need indigenous knowledge to come up with good teachers?! I think if they (teacher trainees) receive proper content and pedagogical skills then ... I think that's all they need. (Statement made by a language teacher in one of the schools where School of Education Luganda language trainee teachers carry out their school practice.)

The above findings imply that indigenous knowledge is transmitted but constrained by the pedagogy used and the attitude of some of the language teachers in the field.

\subsection{Teacher trainers and trainees 'awareness and understanding of indigenous knowledge in language education curriculum}

The interview data revealed that $73 \%$ of the teacher trainers were aware of the indigenous knowledge embedded in language education curriculum. While all the sampled language lecturers were aware which component of the curriculum had indigenous knowledge and that which did not? The study also revealed that about $48 \%$ of the $73 \%$ of the sampled students had a mixed conception what 
indigenous knowledge is and a corrupted African knowledge, values and beliefs.

On the other hand findings from the interview revealed that there numerous skills and values embedded in indigenous knowledge. It was disclosed by some participants that if indigenous knowledge is discussed and integrated in the language teacher curriculum, then teacher trainees would acquire skills that are pertinent to their profession and equally significant for their survival. Data from focus group discussions and interviews mentioned psychomotor skills such as entrepreneurial skills; affective values and attitudes such as appreciation of traditional knowledge and its role in development; and also socio-cultural and cognitive skills that are relevant to individual and societal growth and development. One of the teacher trainers pointed out and said:

"It is basically through indigenous knowledge that student teachers [teacher trainees] acquire emotional intelligence. It [indigenous knowledge] makes a lot of sense to them than the theoretical knowledge that we give them"

Another interviewee (teacher trainer) also reiterated the significance of skills acquired as a result of exposing teacher trainees to indigenous knowledge. She observed:

“... that knowledge [indigenous knowledge] broadens the understanding of our students [teacher trainees], and widens their perception of the work environment after school"

Responses from the focus group discussions underscored the relevance of indigenous knowledge in enabling language teacher trainees to attain pedagogical skills. It is necessary 'for development planners to take into account the accumulated knowledge and traditional skills and technology of the people among whom they work (Brokensha, Warren \& Werner, 1980). Development efforts that ignore local circumstances, local technologies, and local systems of knowledge have wasted enormous amounts of time and resources. 'Compared with many modern technologies, traditional techniques have been tried and tested; are effective, inexpensive, locally available, and culturally appropriate; and in many cases are based on preserving and building on the patterns and processes of nature' (Grenier, 1998: 17). Therefore, Uganda and Africa in general need a new type of education system which is geared towards preparing learners to acquire knowledge necessary for addressing societal challenges (Tedla, 1995).

The observed data revealed that the areas in the curriculum where indigenous knowledge is presented are not discussed thoroughly in the teaching-learning process. As much as participants (teacher trainers) in the interviews pointed out that they go an extra mile to discuss IK concepts and issues, the teacher trainees did not seem to possess substantial IK knowledge and skills during their 
training. Besides, the data disclosed that English and Luganda teacher trainers did not possess substantial or deeper knowledge on indigenous knowledge. This basically means that the English and Luganda teacher trainees hardly acquire indigenous knowledge, values and skills when they are being trained to become teachers. However, a substantial number of scholars in the fields of physical and biological sciences, Anthropology, agriculture, agro forestry, hydrology and Education are realising the increasing need of exploring indigenous knowledge in a bid to understand their fields better, and perpetuate research in those fields. 'Scientific knowledge systems have received increased criticism within the social science literature while indigenous knowledge systems are often over-optimistically presented as viable alternative ways of knowing' (De Walt, 1994).

The study further revealed that the mode of delivery in public universities and the entire process of training language teachers at Makerere University did not put much emphasis on indigenous knowledge. This has widened the gap between the skills required in the market place and the skills obtained from the university. This concurs with the findings of Cloete, Pillay, Bunting \& Maassen, 2011 on the link between the skills obtained at Makerere University and their impact on national development. There is a discrepancy between the skills obtained at the university and the needs of the community. Of late, IK has been lauded as an alternative collective wisdom relevant to a variety of matters at a time when existing norms, values and laws are increasingly called into question (Berkes, 1993).

\section{Conclusion and Recommendations}

The study established that both the language teacher trainers and trainees had little knowledge about indigenous knowledge. This was as a result of the failure of the language teacher curriculum to consider indigenous knowledge as an essential component in the training of both English and Luganda teachers. Therefore, the contribution of indigenous knowledge to the knowledge, skills and attitudes of trainees is negligible. The absence of a formidable anchor in terms of indigenous knowledge, where knowledge, skills and attitudes set off and sprout, has crippled the originality and creativity of both English and Luganda teacher trainees. The following recommendations are suggested:

There is an urgent need to document the existing indigenous knowledge systems in all the different ethnic backgrounds from Uganda, and select those systems or some of their strands that are regarded as relevant to language teacher trainees. Much of the indigenous knowledge systems in Uganda are not documented, and what exists, is in form of illustrations scattered from one 
document to another. A systematic documentation of this knowledge could be carried out through employing both empirical and ethnographic research. The presentation and organisation of this data should clearly spell out the knowledge; skills and attitudes learners should gain after coming into contact with a curriculum where indigenous knowledge is part and parcel of the programme.

After substantial data had been collected and analysed, then a reform of the existing language teacher curriculum at Makerere University should take place. For indigenous knowledge to have a substantial impact on both English and Luganda language teacher trainees, it should be integrated into the content and methodology of the language teacher curriculum. This is because the curriculum content and means of delivering should be rooted in traceable and familiar knowledge, skills and attitudes. Indigenous knowledge should become an anchor onto which the training of teacher trainees sprouts from.

\section{References}

Achebe, C (1958) Things Fall Apart. East African Educational Publisher. Nairobi. Achebe, C (1960). No longer at Ease. Heinemann, Nairobi.

Akankwasa R.R (1997) Formal education and the Survival of Indigenous cultures in the era of Global modernization: Insights from some Ugandan schools Mawazo

Berkes, F. (1993). Traditional Ecological Knowledge in Perspective. In J.T. Inglis (Ed.). Traditional Ecological Knowledge: Concepts and Cases. Ottawa: International Programme on Traditional Ecological Knowledge and International Development Research Centre.

Bray, M., Peter C. and D. Stephens (2000). "Indigenous Forms of Education: The Individual and Society" in Brock-Unte, Birgit. Whose Education for All: Re-colonization of the African Mind. New York: Falmer Press.

Brokensha, D.W.; Warren, D.M. \& Werner, O. (1980). Indigenous Knowledge Systems and Development. Washington DC: University Press of America.

Cloete, N.; Bailey, T.; Pillay, P.; Bunting, I. \& Maassen, P. (2011). Universities and Economic Development in Africa. Wynberg: Centre for Higher Education Transformation (GHET).

De Walt, B.R. (1994). Using Indigenous Knowledge to Improve Agriculture and Natural Resource Management. In Human Organisation. 53 (2), pp. 123131.

Grenier, L. (1998). Working with Indigenous Knowledge: A Guide for Researchers. Ottawa: International Development Research Centre. 
Ibingira G S K (1973) The forging of an African Nation Thee Political and Constitutional Evolution of Uganda from Colonial rule to independence 1894-1962 The Viking Press New York

Kagoda A. M. (2002) Education and construction of African Identity. Cited in Reflections on Education in Africa Loccumer Protokoller5/02

Kampala Roman Catholic Arch diocesan archives 1877 to 2012

Kwitonda, A. 1995. 'A century of school and education in Uganda. In Okoth, P. G; Muranga, M; Ogwang, E. O. (eds.) Uganda: A Century of Existence. Kampala: Fountain publishers.

Mbiti, J.S (1980) African Religions and philosophy Heinemann, Nairobi.

Mulumba, M. B. \& Masagazi, M. F. (2012). Challenges to African Development: The Medium of Instruction in Uganda's Education System. In Pedagogy, Culture \& Society, 20 (3), 435-450.

Mulumba, M.B. (2011). Management of Language Education Programmes and Training of Language Teachers in Public Universities in Uganda. PhD Thesis, Makerere University.

NAPE report 2010/12

Ngũgĩ wa Thiong'o (1965) The River Between. Heinemann, Nairobi.

Obeng E. A. (1991) The Religious Experience and the Environment: Implications for Religious Understanding. Journal of African Religions and Philosophy. Vol. 2 No. 1.

Ociti P. J. (1990) An Introduction to Indigenous education in East Africa. Kampala: School of Education Makerere University.

Tedla, E. (1995). Sankofa: African Thought and Education. New York: Peter Lang.

Warren, D.M.; Slikkerveer, L.J. \& Brokensha, D. (1995). The Cultural Dimension of Development: Indigenous Knowledge Systems. London: Intermediate Technology Publications.

Zulu, I. M. (2006). Critical indigenous African education and knowledge. Journal of Pan African Studies. 1 (3), 32-49.

(Kampala Archdiocesan archives 2012)

The Nordic Africa Institute (2011). African languages in /and African engagements: A call for re-consideration (Panel 149). In the Conference Book of the $4^{\text {th }}$ European Conference on African Studies. 15-18 ${ }^{\text {th }}$ June, 2011, Uppsala, Sweden. 
